
\title{
$\begin{array}{ll}\text { Research Square } & \begin{array}{l}\text { Preprints are preliminary reports that have not undergone peer review. } \\ \text { They should not be considered conclusive, used to inform clinical practice, } \\ \text { or referenced by the media as validated information. }\end{array}\end{array}$
}

\section{Assessment of Body Composition in Obese Pediatric Patients: a Method Comparison}

\section{Alexandra Thajer ( $\nabla$ alexandra.thajer@meduniwien.ac.at )}

Department of Pediatrics and Adolescent Medicine, Division of Pediatric Pulmonology, Allergology and Endocrinology, Medical University of Vienna, Waehringer Guertel 18-20, 1090 Vienna, Austria

Gabriele Skacel

Department of Pediatrics and Adolescent Medicine, Medical University of Vienna

Katharina Truschner

Department of Pediatrics and Adolescent Medicine, Medical University of Vienna

\section{Anselm Jorda}

Department of Pediatrics and Adolescent Medicine, Medical University of Vienna

\section{Martin Vasek}

Department of Pediatrics and Adolescent Medicine

\section{Brian Horsak}

Fachhochschule St Polten Department Gesundheit

\section{Johanna Strempfl}

Fachhochschule St Polten Department Gesundheit

\section{Alexandra Kautzky-Willer}

Department of Internal Medicine III, Medical University of Vienna

\section{Franz Kainberger}

Department of Biomedical Imgaing and Imgae-Guided Therapy, Medical University of Vienna

\section{Susanne Greber-Platzer}

Department of Pediatrics and Adolescentr Medicine, Medical University of Vienna

\section{Research article}

Keywords: Pediatric obesity, Body composition analysis, Bioelectrical impedance analysis, Air displacement plethysmography, DXA, Body fat percentage, Fat mass, Fat free mass

Posted Date: October 21st, 2020

DOI: https://doi.org/10.21203/rs.3.rs-93839/v1

License: (c) (i) This work is licensed under a Creative Commons Attribution 4.0 International License. Read Full License 


\section{Abstract}

\section{Background}

The determination of body composition is an important method to investigate obese patients and to evaluate the efficacy of medical interventions. Bioelectrical impedance-based methods are convenient, non-invasive and widely applied for this purpose, but need to be validated for their use in young obese patients.

\section{Methods}

We compiled data from three independent studies on different aspects of obesity in children and adolescents, measuring body composition with two bioelectrical impedance-based devices (TANITA and BIA). Further, for a small patient group additional data were collected with air displacement plethysmography (BOD POD) and DXA.

\section{Results}

Both, the combined data of the entire study population of 123 patients (age: $6-18$ years, BMl: $21-59 \mathrm{~kg} / \mathrm{m}^{2}$ ) and the data of each individual study, showed that TANITA and BIA yield significantly different results on body composition, with TANITA overestimating body fat percentage and fat mass relative to BIA and underestimating fat-free mass $(p<0.001$ for all three parameters). A Bland-Altman plot revealed that both methods show little agreement and produce clinically relevant differences for all three parameters. In addition, we detected gender-specific differences with both methods, body fat percentage being significantly lower $(p<0.01)$ and fat-free mass significantly higher $(p<0.001)$ in males than females. A comparison of bioelectrical impedance-based methods with BOD POD and DXA on a small patient group indicated no significant difference between methods.

\section{Conclusions}

Both bioelectrical impedance-based methods provide significantly different results on body composition in young obese patients and the data thus cannot be used interchangeably. Routine clinical practice may nonetheless use these devices but must adhere to a specific device for repetitive measurements to ascertain comparability of data.

Trial registration: Study\#2, Children`s KNEEs study, ClinicalTrials NCT02545764. Registered 10 September 2015, https://clinicaltrials.gov/ct2/show/results/NCT02545764

\section{What Is Already Known?}

- Obesity in children is a health issue of increasing relevance, with early obesity enhancing the risk for multiple diseases later on.

- Diagnosing obesity and evaluating the efficacy of medical interventions require accurate and reproducible determination of body composition.

- Body composition changes during juvenile development and thus body composition assessment methods require validation for their use in children and adolescents.

\section{What Is New?}

- Previously detected differences between body composition measurements with different devices based on bioelectrical impedance could be reproducibly confirmed in independent studies on a larger patient population.

- The TANITA scale consistently overestimated body fat percentage and fat mass relative to BIA-BIACORPUS device and vice-versa underestimated fat-free mass. 
- A comparison of bioelectrical impedance-based methods with BOD POD and DXA on a small patient group indicated no significant differences in body fat percentage, fat mass and fat-free mass, and showed the best agreement in these data between TANITA and DXA.

- Given the ease of use, the TANITA scale may be applied to obtain data on body composition in young obese patients, but must be adhered if repetitive measurements over time are required to assess the impact of interventions.

\section{Background}

Obesity is a health issue of world-wide relevance and of increasing prevalence, considered to have reached the level of a pandemic disease over the past 50 years [1]. Besides the often-perceived general reduction of quality of life, obesity is known to profoundly increase the risk for numerous diseases such as diabetes [2], cardiovascular diseases [3], cancer [4], and, as became recently evident, the severity of viral diseases such as Covid-19 [5, 6]. Importantly, the enhanced prevalence of obesity is already detectable in children and adolescents and a recent study found that $90 \%$ of obese children at the age of 3 years have overweight at adolescence [7], and almost $60 \%$ with obesity at 2 to 19 years were predicted to be obese at an age of 35 years [8]. Thus, the early detection of signs indicating enhanced risk of developing obesity such as unusually high body fat or body fat percentage during childhood and adolescence appears of critical importance to allow to take preventive measures or to initiate medical interventions before the development of obesity-related diseases is triggered.

Among the different methods to diagnose overweight and obesity, the determination of body fat and of total body composition is of particular relevance. Different approaches for correct classification include measurements with bioelectrical impedance [9], air displacement plethysmography [10], and dual x-ray absorptiometry (DXA) [11], all of which are reportedly used in clinical practice. However, although these methods are well established for the application with adult patients, data on their use in obese children and adolescence are associated with considerable uncertainty, since several assumptions underlying these methods may be valid in adults but not in children. For example, changes in protein, water and mineral content occur during growth and maturation and affect the estimates of percent fat and fat-free mass [12]. Also, the share of different body compartments is not a constant from childhood to adulthood [13]. Thus, methods applied to determine body composition in adults need to be validated for their use in children $[12,14]$. In addition, as different methods may produce variable results, it is important to know how these methods compare with each other to be able to set into perspective data generated using a particular methodology.

Recently, we could publish differences related to body composition in obese children with two methods based on bioelectrical impedance, TANITA and BIA [15]. These data were based on a small study population, but still indicated that TANITA overestimated body fat percentage and fat mass and underestimated fat free mass compared to BIA [15]. Therefore, we wanted to reevaluate these results in a larger study population and with several devices for determination of body composition in children and adolescents. Data on body composition assessments of obese children were obtained with TANITA and BIA and these bioelectrical impedance-based data were compared to air displacement plethysmography BOD POD and DXA.

\section{Methods}

\section{Patient recruitment}

Data from patients of three different studies performed at the Medical University Vienna were analyzed. The patients were in medical control of the outpatient clinic of pediatric obesity, dyslipidemia and nutritional medicine at the Department of Pediatrics and Adolescent Medicine, Vienna.

Study\#1, the BODCOP study - a retrospective study between August 2015 and May 2016, included 67 children and adolescents. All patients were aged under 18 years and had a body mass index (BMI) exceeding the $97^{\text {th }}$ percentile according 
to the recommendations given by Kromeyer-Hauschild and colleagues [16]. The study was approved by the local EthicsCommittee of the Medical University Vienna (EC Nr: 1357/2016).

Study\#2, Children`s KNEEs study - a randomized controlled trial between September 2015 and May 2017, data from 44 patients were collected during a 12-week strength and neuromuscular exercise program for the lower extremity on knee load, pain and function in pediatric patients with obesity [17]. Patients were aged between 10 and 18 years and exceeded the $97^{\text {th }}$ percentile described by Kromeyer-Hauschild [16]. The study was approved by the local Ethics-Committee of the Medical University Vienna (EC Nr: 1445/2013) and was registered at clinicaltrials.gov NCT02545764.

Study\#3, the MotiMove Study - a pilot for an intervention study on movement in obese adolescents between October and December 2019, included 12 patients aged between 14 and 18 years with a BMl exceeding the $90^{\text {th }}$ percentile according to Kromeyer-Hauschild [16]. The Ethical-Committee of the Medical University of Vienna approved the study (EC Nr: 1572/2019). In study\#2 and \#3, written informed consent was obtained from all parents and children.

\section{Anthropometric measurements}

Anthropometric parameters included body height and weight, and circumference at the waist, hip abdomen, and mid upper arm. These latter measures of circumferences, however, were not included in the present analysis. Procedures were as outlined previously [15], but a TANITA scale instead of a SECA scale. In brief, body weight was measured within $0.1 \mathrm{~kg}$ precision in an upright position and in underwear. These values were also applied for calculation of BIA-based body composition determination. Body height was measured in an upright facing position with feet together and the back against the wall to the nearest $0.1 \mathrm{~cm}$ as the maximum distance between the floor and the highest point on the head.

\section{Measurements of body composition}

The present study applied four different methods for the assessment of body composition, two of these based on bioelectrical impedance (TANITA, BIA), one on air displacement plethysmography (BOD POD), and one on dual x-ray absorptiometry (DXA). The main parameters determined and analyzed were body fat percentage (BFP, \%), fat mass (FM, kg) and fat-free mass (FFM, kg). To reduce measurement variability, all measurements in each patient were conducted by the same trained team member, at the same daytime, and the same condition like an empty bladder.

TANITA and BIA

The assessment of body composition with the devices is following standard procedures [15]. Patients were measured with the TANITA scale (Type BC-418MA, TANITA Corporation, Tokyo, Japan) and immediately afterwards with the BIA device (BIACORPUS RX 4000, Medical Healthcare GmbH, Karlsruhe, Germany).

\section{BOD POD}

The determination of body composition with air displacement plethysmography was conducted with the BOD POD Gold Standard Body Composition Tracking System (BOD POD COSMED Inc, USA), following instructions of the manufacturer. This type of measurement applies the principles of whole-body densitometry to determine body composition. For this, a highprecision weight assessment is combined with a body volume measurement and determination of the thoracic gas volume, and then, based on densitometric equations BFP, FM and FFM are calculated.

\section{DXA}

The DXA-based method for the determination of body composition applies the fact that fat and non-fat tissue attenuate xrays to a different extent, allowing to calculate the proportion of each compartment following a whole-body scan.

Whole-body DXA was performed with a Hologic Horizon system A (Marlborough, MA, USA), release 2018, for estimating body composition by the same trained technicians according to the prescriptions by the manufacturer and after daily calibration. 
All patients were placed in supine position with the limbs in standardized way according to the guidelines. The precision and accuracy of DXA is reported as acceptable to define body composition in children [18]. Fat mass, lean tissue mass, and bone mineral content of the whole body were measured. Radiation dose, expressed as dose area product, was $7.9 \mathrm{cGy} \cdot \mathrm{cm}^{2}$.

\section{Statistics}

Statistical analyses were performed with the SPSS software package (SPSS Inc., Chicago, IL, version 24.0). Results are expressed as means \pm SD unless otherwise indicated. Assumptions were checked before conducting parametric tests. Data on body composition methods were analyzed with paired t-tests and a p-value of $<0.05$ was considered as statistically significant. Further, data obtained with TANITA and BIA were compared by the Pearson correlation coefficient, and the BlandAltman plot was used to assess the extent of agreement between the two methods [19]. The $95 \%$ limits of agreement were calculated as the mean difference \pm 1.96 SD [20].

\section{Results}

\section{General characteristics of the study population}

The data obtained from three independent studies were either separately evaluated for each study or presented as a pooled study population. As shown in Table 1, the common patient population consisted of 123 children and adolescents with $63 \%$ male participants and a mean age of 13.6 years, except study \#3 including only adolescents aged 14 to 18 years. The overall BMI was $35.2 \mathrm{~kg} / \mathrm{m}^{2}$ and slightly higher in study group 3 with BMI of $37 \mathrm{~kg} / \mathrm{m}^{2}$.

\section{Comparison of bioelectric impedance-based methods}

Values on body composition determined with the bioelectrical impedance-based methods, TANITA and BIA are summarized in Table 2. In the overall study population with 123 patients, BFP amounted $41.4 \%$ when determined with TANITA and $39.1 \%$ when assessed with the BIA device, a statistically highly significant difference $(p<0.001)$. Similar effects were shown for the FM with an average of $41.6 \mathrm{~kg}$ determined with TANITA and a significantly lower value of $38.6 \mathrm{~kg}$ determined with BIA ( $p<$ 0.001), whereas the average FFM of $56.2 \mathrm{~kg}$ seen with TANITA was significantly lower than that of $58.9 \mathrm{~kg}$ seen with BIA ( $p<$ $0.001)$. These differences were highly significant in patients from study\#1 and \#2, while in study\#3 the differences were not significant, presumably due to the lower patient frequencies.

In a recent study with a smaller population we detected less gender-specific differences. But here TANITA and BIA showed a significant difference in BFP $(p<0.01)$ and FFM $(p<0.001)$ between male and female participants, but not in FM (Table 3). As a result, BFP was lower in males compared to females, and accordingly FFM was considerably higher in males than in females. Therefore, most of these differences were also observed and remained significant in study\#1 and \#2, except BFP in the TANITA of study\#2, and in the BIA of study\#3. Moreover, total FM measured with TANITA was higher in males than females, although this was not significant, whereas FM measured with BIA was equal in both genders or even slightly increased in females.

For further evaluation of differences in body composition determined with TANITA or BIA, Pearson correlation coefficients were used, and Bland-Altman plots generated. As shown in Fig.1, Pearson correlation was highly significant between TANITA and BIA-based determination of BFP (Pearson $r=0.817$; $p<0.01, n=123$ ), of FM (Pearson $r=0.953 ; p<0.01$, $n=123$ ), and of FFM (Pearson $r=0.941 ; p<0.01, n=123$ ). This contrasts with the result obtained with the Bland-Altman plot, which displays the mean difference between the methods $\pm 1.96 \mathrm{SD}$. This analysis indicated important, potentially clinically relevant differences between both methods for BFP, FM and FFM. Thus, the average difference and the $95 \%$ limits of agreement amounting to $-2.27 \%$ (average) and from $-11.17 \%$ to $6.62 \%$ (range) for BFP, to $-2.93 \mathrm{~kg}$ (average) and from $-14.81 \mathrm{~kg}$ to 8.95 $\mathrm{kg}$ (range) for FM, and to $2.69 \mathrm{~kg}$ (average) and from $-8.17 \mathrm{~kg}$ to $13.56 \mathrm{~kg}$ (range) for FFM.

\section{Comparison of BOD POD- and DXA-based determination of body composition}


In study\#3 the body composition from 12 individuals was obtained with TANITA and BIA, and 7 were also subjected to comparative measurements using air displacement plethysmography and DXA-based assessments. In this sub-group, three persons were male (43\%), the average age was $16.1 \pm 1.5$ years, and mean ( \pm SD) values for height, weight and BMI were $166.9 \pm 10.2 \mathrm{~cm}, 105.1 \pm 17.3 \mathrm{~kg}$, and $37.0 \pm 4.7 \mathrm{~kg} / \mathrm{m}^{2}$, respectively.

Despite of apparent differences, the most pronounced related to the determination of FM (ranging from 48.6 to $53.2 \mathrm{~kg}$ ), due to the small sample size, we could not detect significant differences between methods (Table 4). Overall, there was a satisfying agreement for the BFP values, only BOD POD determined somewhat higher values, and a greater variability for FM, which was lowest with BIA, and a reasonably good agreement for values on FFM. Gender-specific differences for BFP and FFM were similar for all groups, but never significant.

\section{Discussion}

Bioelectrical impedance-based determination of body composition is a relatively simple method, not very time-consuming, non-invasive, and does not exposure the patient to radiation [9]. Therefore, it is widely applied in clinical practice and appears ideally suited for the use with children and adolescents. However, there are different devices available using bioelectrical impedance measuring principles and limited data on young obese patients. Accordingly, we considered to evaluate different devices and to compare these with each other to obtain insight into the accuracy of the methods for the determination of body composition in obese patients during childhood and adolescence.

In line with a previous study [15], our current assessment, using a much larger sample size ( $\mathrm{N}=123$ as compared to 38$)$, confirmed that body composition determination in young obese patients yields significantly different results depending on whether it is conducted using the TANITA or the BIA device. Thus, TANITA-based determination of body composition overestimated BFP and FFM relative to BIA, and significantly underestimated FFM. Importantly, this was confirmed in three entirely independent studies and only at very small sample sizes, data variability blurred this difference. Further, while Pearson correlation indicated an expected association for all three parameters between both methods, Bland-Altmann plot tests established clinically relevant differences. At an average BFP of around $40 \%$ measured with both methods a difference of $-2.3 \%$ may not seem excessive. However, as these differences ranged from -11 to $6.6 \%$ which appears rather large. In addition, the discrepancy between the methods increased at higher values of BFP, resulting in little agreement in the upper range of the data. Similar discrepancies were determined for FM, which differed by $\pm 12 \mathrm{~kg}$ at a mean of around $40 \mathrm{~kg}$ and displayed considerable skewness in the upper data range, and for FFM with a $\pm 11 \mathrm{~kg}$ range at a mean of around $57 \mathrm{~kg}$. It seems obviously that body composition should be measured with the same bioelectrical impedance-based method, TANITA or BIA to obtain matching values and should not be changed during follow-up or for the study population group. This is in line with findings on adolescent obese patients [21] and on obese adult women, the latter study comparing TANITA with yet another device based on the same measuring principle [22].

We could also confirm previously indicated gender-related differences in body composition [15]. Independent from the bioelectrical impedance-based method, male patients had significantly lower BFP and significantly higher FFM, whereas FM did not differ between genders. Similar differences were noted for BFP and FM, but not for FFM in the small study\#3 group consisting of seven patients examined with BOD POD and DXA. Physiologically, these differences may reflect the larger muscle mass in males and the enhanced fat deposition in developing females [23]. Overall, these data underline that gender differences need to be taken into account when comparing different groups [24].

For the same patient group the four methods for body composition, TANITA, BIA, BOD POD and DXA showed a good agreement for BFP and FFM, but a higher variability for FM. DXA is described as a reference method for body composition determination $[11,18]$ and agreed very well with the TANITA-based measurements in this study. The disadvantages of DXA are the limited availability in centers and the exposure to radiation. It appears that TANITA could be appropriate to measure body composition in young obese patients. However, although previous studies found that bioelectrical impedance-based methods may be accurate enough to provide reliable measurements $[25,26]$, in other studies a more limited reliability was 
defined [21, 27, 28], except for obese, but not morbid obese patients [29], or a clear need of optimization for young obese patients [30], highlighting the need to be cautious when applying it.

\section{Conclusions}

The evaluation of data from three independent studies in young obese patients could show that the body composition differed significantly for BFP, FM and FFM depending on the measurement with TANITA or BIA. A small-scale comparison with air displacement plethysmography and DXA indicated that TANITA shows the best agreement with DXA, widely considered a reference method. Thus, we suggest that the easily applicable and non-invasive TANITA device may be most suitable for clinical routine in obese patients in childhood and adolescence but needs to be strictly adhered to in order to receive reliable repetitive data.

\section{List Of Abbreviations}

BFP: Body fat percentage; BIA: Bioelectrical impedance analysis; BMI: Body mass index; DXA: Dual energy $x$-ray absorptiometry; FFM: Fat free mass; FM: Fat mass

\section{Declarations}

\section{Acknowledgements}

We would like to thank all children and adolescents, who have participated in these three studies. The authors also thank the BODCOP, Children`s KNEEs, the MotiMove study team and Thomas Thajer for his great assistance ensuring that any figures are of sufficient quality to be clearly legible.

\section{Funding}

The Children's KNEEs study was funded by NFB - Lower Austrian Research and Education Company and Provincial Government of Lower Austria, Department of Science and Research (LSC13-009).

\section{Availability of data and materials}

Data and intervention materials are available upon request to the corresponding author.

\section{Authors' contributions}

AT has conceived of the study design, carried out data analyses and wrote the manuscript.

AT, KT, GS, AJ, and MV performed the body composition measurements and data collection. BH designed the main Children's KNEEs study and JS the MotiMove study and provided critical review. AK-W, FK and SG-P provided measuring equipment and their expertise and reviewed the manuscript. All authors have read and approved the published version of the manuscript.

\section{Ethics approval and consent to participate}

The three independent studies were approved by the Institutional Review Board of the Medical University Vienna (study\#1: EC Nr: 1357/2016; study\#2: EC Nr: 1445/2013; and study\#3: EC Nr: 1572/2019). Written consent was obtained from patients and legal representatives. 


\section{Consent for publication}

Not applicable.

\section{Competing interests}

The authors declare that they have no competing interests.

\section{References}

1. Blüher M. Obesity: global epidemiology and pathogenesis. Nature Reviews Endocrinology. 2019;15:288-98. doi:10.1038/s41574-019-0176-8.

2. Bhupathiraju SN, Hu FB. Epidemiology of obesity and diabetes and their cardiovascular complications. Circ Res. 2016;118:1723-35. doi:10.1161/CIRCRESAHA.115.306825.

3. Cercato C, Fonseca FA. Cardiovascular risk and obesity. Diabetology and Metabolic Syndrome. 2019;11:1-15. doi:10.1186/s13098-019-0468-0.

4. Allott EH, Hursting SD. Obesity and cancer: Mechanistic insights from transdisciplinary studies. Endocrine-Related Cancer. 2015;22:R365-86. doi:10.1530/ERC-15-0400.

5. de Siqueira JVV, Almeida LG, Zica BO, Brum IB, Barceló A, de Siqueira Galil AG. Impact of obesity on hospitalizations and mortality, due to COVID-19: A systematic review. Obes Res Clin Pract. 2020. doi:10.1016/j.orcp.2020.07.005.

6. Kass DA, Duggal P, Cingolani O. Obesity could shift severe COVID-19 disease to younger ages. The Lancet. 2020;395:1544-5. doi:10.1016/S0140-6736(20)31024-2.

7. Geserick M, Vogel M, Gausche R, Lipek T, Spielau U, Keller E, et al. Acceleration of BMI in Early Childhood and Risk of Sustained Obesity. N Engl J Med. 2018;379:1303-12. doi:10.1056/NEJMoa1803527.

8. Ward ZJ, Long MW, Resch SC, Giles CM, Cradock AL, Gortmaker SL. Simulation of Growth Trajectories of Childhood Obesity into Adulthood. N Engl J Med. 2017;377:2145-53. doi:10.1056/NEJMoa1703860.

9. Ward LC. Bioelectrical impedance analysis for body composition assessment: reflections on accuracy, clinical utility, and standardisation. European Journal of Clinical Nutrition. 2019;73:194-9. doi:10.1038/s41430-018-0335-3.

10. Fields DA, Gunatilake R, Kalaitzoglou E. Air displacement plethysmography: Cradle to grave. Nutr Clin Pract. 2015;30:219-26. doi:10.1177/0884533615572443.

11. Shepherd JA, Ng BK, Sommer MJ, Heymsfield SB. Body composition by DXA. Bone. 2017;104:101-5. doi:10.1016/j.bone.2017.06.010.

12. Lohman TG, Going SB. Body composition assessment for development of an international growth standard for preadolescent and adolescent children. Food Nutr Bull. 2006;27 4 SUPPL. doi:10.1177/15648265060274s512.

13. Weber DR, Leonard MB, Zemel BS. Body composition analysis in the pediatric population. Pediatr Endocrinol Rev. 2012;10:130-9. /pmc/articles/PMC4154503/?report=abstract. Accessed 31 Jul 2020.

14. Wells JCK, Williams JE, Chomtho S, Darch T, Grijalva-Eternod C, Kennedy K, et al. Body-composition reference data for simple and reference techniques and a 4-component model: A new UK reference child. Am J Clin Nutr. 2012;96:1316-26. doi:10.3945/ajcn.112.036970.

15. Kreissl A, Jorda A, Truschner K, Skacel G, Greber-Platzer S. Clinically relevant body composition methods for obese pediatric patients. BMC Pediatr. 2019;19. doi:10.1186/s12887-019-1454-2.

16. Kromeyer-Hauschild K, Wabitsch M, Kunze D, Geller F, Geiß HC, Hesse V, et al. Percentiles of body mass index in children and adolescents evaluated from different regional German studies. Monatsschr Kinderheilkd. 2001;149:807-18.

doi:10.1007/s001120170107. 
17. Horsak B, Artner D, Baca A, Pobatschnig B, Greber-Platzer S, Nehrer S, et al. The effects of a strength and neuromuscular exercise programme for the lower extremity on knee load, pain and function in obese children and adolescents: Study protocol for a randomised controlled trial. Trials. 2015;16:1-10. doi:10.1186/s13063-015-1091-5.

18. Wohlfahrt-Veje C, Tinggaard J, Winther K, Mouritsen A, Hagen CP, Mieritz MG, et al. Body fat throughout childhood in 2647 healthy Danish children: Agreement of BMI, waist circumference, skinfolds with dual X-ray absorptiometry. Eur J Clin Nutr. 2014;68:664-70. doi:10.1038/ejcn.2013.282.

19. Martin Bland J, Altman DG. Statistical methods for assessing agreenebt between two methods of clinical measurement. Lancet. 1986;327:307-10.

20. Bland JM, Altman DG. Comparing methods of measurement: why plotting difference against standard method is misleading. Lancet. 1995;346:1085-7. doi:10.1016/S0140-6736(95)91748-9.

21. Lazzer S, Boirie Y, Meyer M, Vermorel M. Evaluation of two foot-to-foot bioelectrical impedance analysers to assess body composition in overweight and obese adolescents. Br J Nutr. 2003;90:987-92. doi:10.1079/bjn2003983.

22. Minderico CS, Silva AM, Keller K, Branco TL, Martins SS, Palmeira AL, et al. Usefulness of different techniques for measuring body composition changes during weight loss in overweight and obese women. Br J Nutr. 2008;99:432-41. doi:10.1017/S0007114507815789.

23. Leonard MB, Elmi A, Mostoufi-Moab S, Shults J, Burnham JM, Thayu M, et al. Effects of sex, race, and puberty on cortical bone and the functional muscle bone unit in children, adolescents, and young adults. J Clin Endocrinol Metab.

2010;95:1681-9. doi:10.1210/jc.2009-1913.

24. Kirchengast S. Gender Differences in Body Composition from Childhood to Old Age: An Evolutionary Point of View. J Life Sci. 2010;2:1-10. doi:10.1080/09751270.2010.11885146.

25. Brantlov S, Ward LC, Jødal L, Rittig S, Lange A. Critical factors and their impact on bioelectrical impedance analysis in children: a review. Journal of Medical Engineering and Technology. 2017;41:22-35.

doi:10.1080/03091902.2016.1209590.

26. Leskinen T, Eloranta AM, Tompuri T, Saari A, Ollila H, Mäkelä J, et al. Changes in body composition by age and obesity status in preschool-aged children: the STEPS study. Eur J Clin Nutr. 2020;:1-9. doi:10.1038/s41430-020-0678-4.

27. Sim PY, Su TT, Majid HA, Nahar AM, Jalaludin MY. A Comparison Study of Portable Foot-to-Foot Bioelectrical Impedance Scale to Measure Body Fat Percentage in Asian Adults and Children. Biomed Res Int. 2014;2014. doi:10.1155/2014/475659.

28. Eisenmann JC, Heelan KA, Welk GJ. Assessing body composition among 3- to 8-year-old children: Anthropometry, BIA, and DXA. Obes Res. 2004;12:1633-40. doi:10.1038/oby.2004.203.

29. Verney J, Metz L, Chaplais E, Cardenoux C, Pereira B, Thivel D. Bioelectrical impedance is an accurate method to assess body composition in obese but not severely obese adolescents. Nutr Res. 2016;36:663-70.

30. Lyons-Reid J, Ward LC, Kenealy T, Cutfield W. Bioelectrical impedance analysis-an easy tool for quantifying body composition in infancy? Nutrients. 2020;12:920. doi:10.3390/nu12040920.

\section{Tables}

Table 1. Demographic patient characteristics and anthropometric parameters 


\begin{tabular}{|lllll|}
\hline Characteristics & All patients $(\mathrm{N}=123)$ & Study $1(\mathrm{~N}=67)$ & Study 2 $(\mathrm{N}=44)$ & Study 3 $(\mathrm{N}=12)$ \\
\hline Male (absolute; \%) & $78(63)$ & $43(64)$ & $28(64)$ & $7(58)$ \\
\hline Age (years) & $13.6 \pm 2.6$ & $13.4 \pm 2.6$ & $13.3 \pm 2.4$ & $15.9 \pm 1.4$ \\
\hline Height $(\mathrm{cm})$ & $165.2 \pm 12.1$ & $165.0 \pm 12.7$ & $164.2 \pm 11.4$ & $169.8 \pm 10.4$ \\
\hline Weight $(\mathrm{kg})$ & $97.5 \pm 27.6$ & $98.0 \pm 28.7$ & $94.0 \pm 27.1$ & $107.4 \pm 21.8$ \\
\hline BMI $\left(\mathrm{kg} / \mathrm{m}^{2}\right)$ & $35.2 \pm 7.0$ & $35.4 \pm 7.5$ & $34.3 \pm 6.8$ & $37.0 \pm 4.7$ \\
\hline
\end{tabular}

Results are presented as means \pm SD or as numbers of subjects (\%); BMI body mass index authors declare that they have no competing interests.

Table 2. Comparison of body composition parameters as determined with bioelectrical impedance-based methods.

\begin{tabular}{|c|c|c|c|c|c|c|c|c|c|c|c|c|}
\hline \multirow[b]{2}{*}{ Parameter } & \multicolumn{3}{|c|}{$\begin{array}{l}\text { All patients } \\
(\mathrm{N}=123)\end{array}$} & \multicolumn{3}{|c|}{ Study $1(\mathrm{~N}=67)$} & \multicolumn{3}{|c|}{ Study $2(N=44)$} & \multicolumn{3}{|c|}{ Study $3(\mathrm{~N}=12)$} \\
\hline & TANITA & BIA & $\begin{array}{l}\mathrm{p}- \\
\text { value }\end{array}$ & TANITA & $\mathrm{BIA}$ & $\begin{array}{l}\mathrm{p}- \\
\text { value }\end{array}$ & TANITA & $\mathrm{BIA}$ & $\begin{array}{l}\mathrm{p}- \\
\text { value }\end{array}$ & TANITA & $\mathrm{BIA}$ & $\begin{array}{l}\mathrm{p}- \\
\text { value }\end{array}$ \\
\hline BFP (\%) & $\begin{array}{l}41.4 \pm \\
7.8\end{array}$ & $\begin{array}{l}39.1 \\
\pm \\
6.7\end{array}$ & 0.000 & $\begin{array}{l}41.6 \pm \\
8.1\end{array}$ & $\begin{array}{l}39.4 \\
\pm \\
6.8\end{array}$ & 0.000 & $\begin{array}{l}40.7 \pm \\
7.7\end{array}$ & $\begin{array}{l}37.9 \\
\pm \\
6.0\end{array}$ & 0.000 & $\begin{array}{l}43.0 \pm \\
7.0\end{array}$ & $\begin{array}{l}42.1 \\
\pm \\
8.2\end{array}$ & 0.481 \\
\hline $\mathrm{FM}(\mathrm{kg})$ & $\begin{array}{l}41.6 \pm \\
17.8\end{array}$ & $\begin{array}{l}38.6 \\
\pm \\
14.3\end{array}$ & 0.000 & $\begin{array}{l}41.8 \pm \\
18.5\end{array}$ & $\begin{array}{l}39.0 \\
\pm \\
14.6\end{array}$ & 0.000 & $\begin{array}{l}39.3 \pm \\
17.4\end{array}$ & $\begin{array}{l}36.3 \\
\pm \\
13.8\end{array}$ & 0.001 & $\begin{array}{l}48.6 \pm \\
14.5\end{array}$ & $\begin{array}{l}45.2 \\
\pm \\
12.7\end{array}$ & 0.252 \\
\hline FFM (kg) & $\begin{array}{l}56.2 \pm \\
14.2\end{array}$ & $\begin{array}{l}58.9 \\
\pm \\
16.2\end{array}$ & 0.000 & $\begin{array}{l}56.2 \pm \\
14.3\end{array}$ & $\begin{array}{l}59.1 \\
\pm \\
16.9\end{array}$ & 0.000 & $\begin{array}{l}54.7 \pm \\
13.6\end{array}$ & $\begin{array}{l}57.7 \\
\pm \\
15.4\end{array}$ & 0.001 & $\begin{array}{l}61.3 \pm \\
15.9\end{array}$ & $\begin{array}{l}62.1 \\
\pm \\
15.6\end{array}$ & 0.520 \\
\hline
\end{tabular}

Results are presented as mean $\pm S D$; bold values indicate significant difference at the $p<0.05$ level; comparison of the body composition methods was made using paired samples t-test; BFP body fat percentage, FM fat mass, FFM fat free mass

Table 3. Gender-specific values of body composition parameters determined with TANITA and BIA 


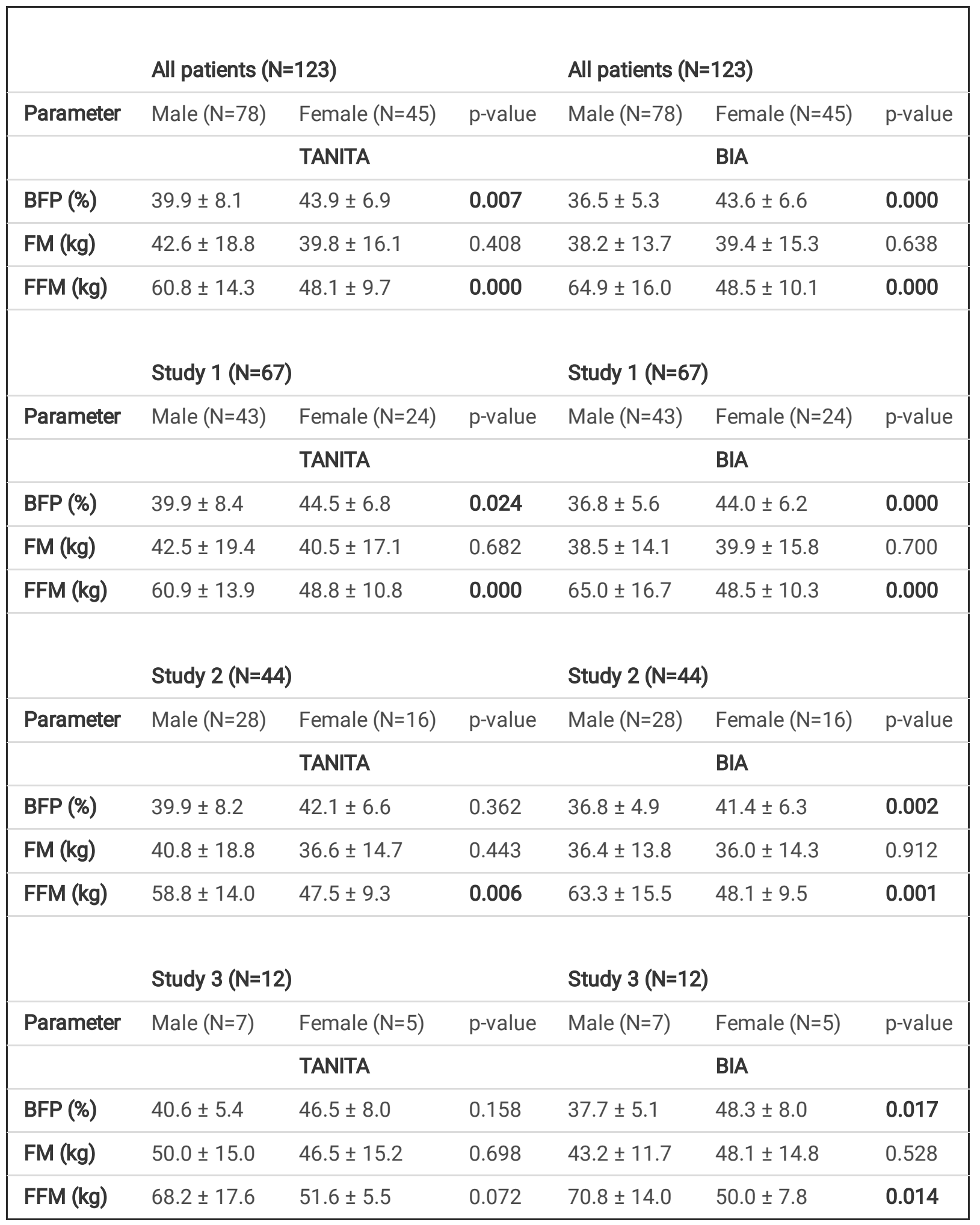

Results are presented as mean $\pm S D$; bold values indicate significant difference at the $p<0.05$ level; comparison of the body composition methods was made using independent samples t-test; BFP body fat percentage, FM fat mass, FFM fat free mass

Table 4. Comparison of body composition data obtained with TANITA, BIA, BOD POD and DXA 


\begin{tabular}{|lllll|}
\hline Parameter & TANITA & BIA & BODPOD & DXA \\
\hline BFP (\%) & $46.3 \pm 7.3$ & $46.0 \pm 8.0$ & $48.5 \pm 4.8$ & $46.8 \pm 3.4$ \\
\hline FM $(\mathrm{kg})$ & $53.2 \pm 16.3$ & $48.6 \pm 12.1$ & $50.6 \pm 8.0$ & $51.5 \pm 7.7$ \\
\hline FFM $(\mathrm{kg})$ & $56.1 \pm 11.2$ & $56.6 \pm 12.5$ & $54.5 \pm 12.2$ & $56.6 \pm 10.7$ \\
\hline
\end{tabular}

Results are presented as mean $\pm S D, n=7$; bold values indicate significant difference at the $p<0.05$ level; comparison of the body composition methods was made using paired samples t-test; BFP body fat percentage, FM fat mass, FFM fat free mass

\section{Figures}

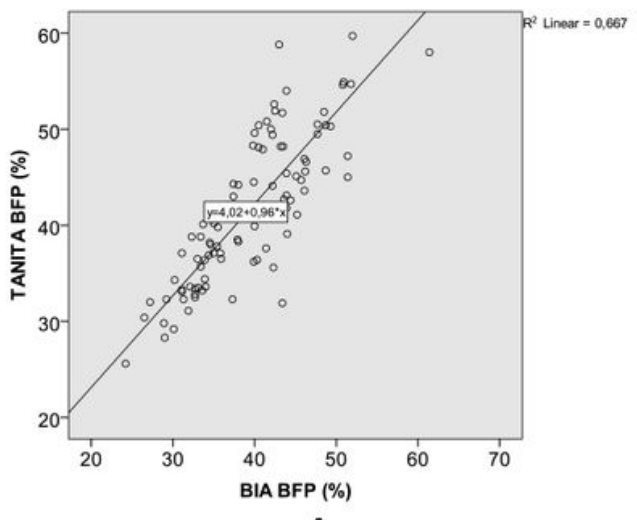

A

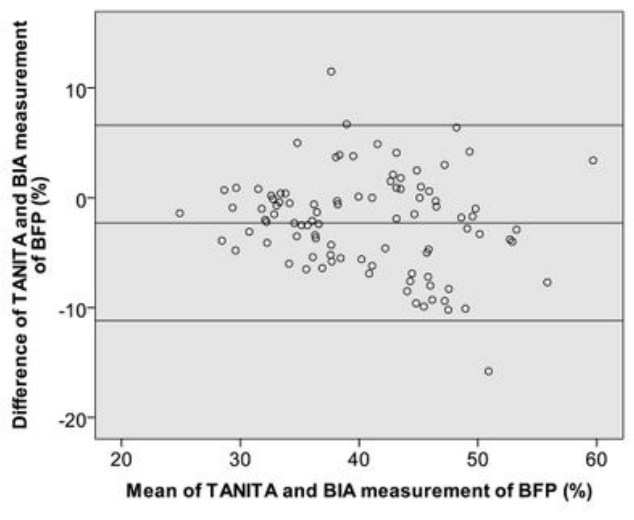

B

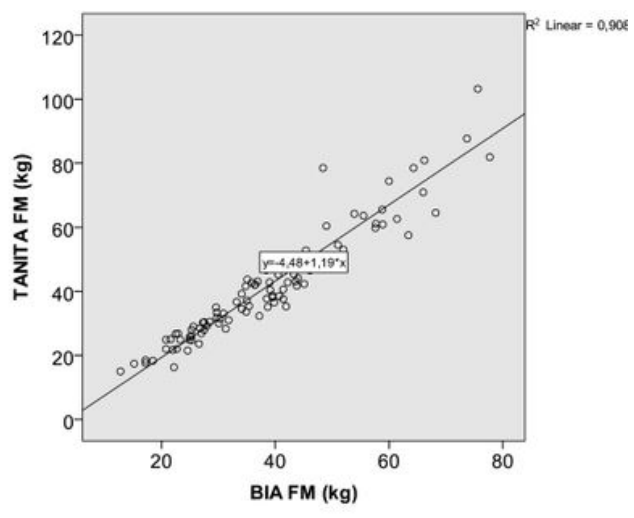

C
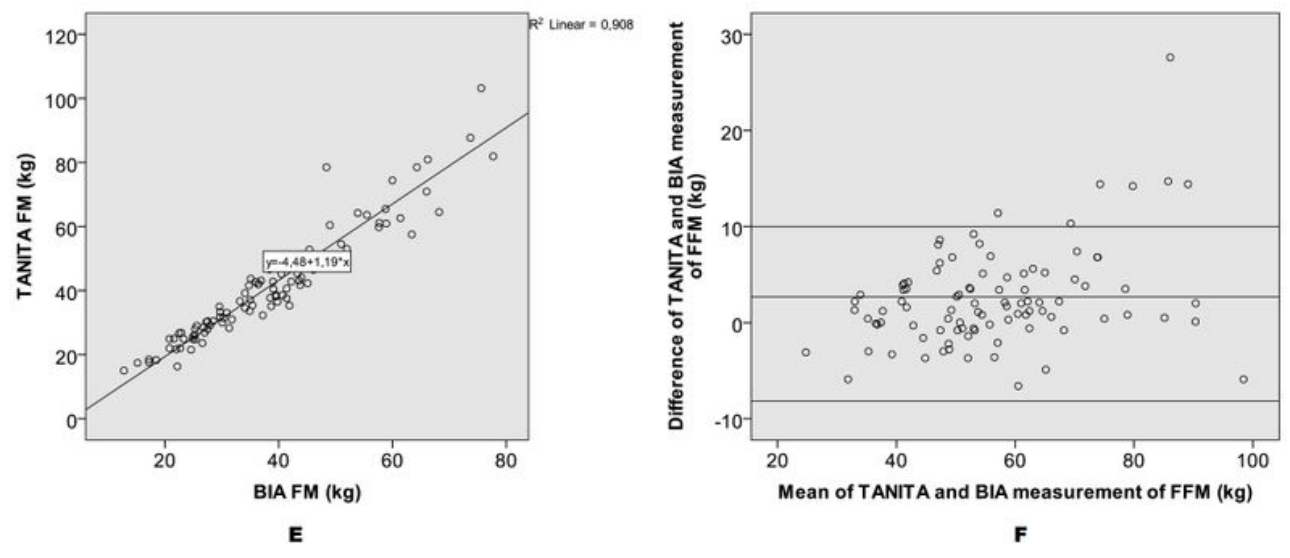

Figure 1

Pearson correlation analysis and Bland-Altman plot of body composition data obtained with TANITA and BIA. Left panel:

Pearson correlation for body fat percentage (a), fat mass (c), and fat free mass (e), with R2 and the equation of the best linear fit given for each correlation plot. Right panel: Bland Altman plots for body fat percentage (b), fat mass (d), fat free mass (f), with the middle line indicating the mean difference and the upper and lower line representing limits of agreement. BFP = body fat percentage, $F M=$ fat mass, $F F M=$ fat-free mass. 